\title{
APORIAS DE UMA DUPLA CRISE: HISTÓRIA E MEMÓRIA DIANTE DE NOVOS ENQUADRAMENTOS TEÓRICOS
}

\author{
Marcos Napolitano ${ }^{1}$
}

Na mitologia grega, Mnemosine, a titânida esposa de Zeus, deusa da memória, e Clio, a musa da história, são mãe e filha. Mnemosine luta contra o esquecimento, e o faz a partir da perspectiva da infinitude. Portanto, Mnemosine seleciona, discrimina, guarda e enumera o que deve ser lembrado, evitando que o rio do esquecimento leve em suas águas todos os fatos e experiências passadas. Clio, como boa musa, inspira os homens a criar, mas também a celebrar tudo que fizeram no mundo. Nesta luta comum contra o esquecimento, ainda que por caminhos diferenciados, ambas nunca tiveram uma relação fácil entre si, apesar do parentesco e dos laços afetivos. ${ }^{2}$

Esta imagem, um tanto recorrente nas reflexões sobre história e memória, é apenas uma porta de entrada para pensar a relação complexa e multidirecional entre ambas, tema que dificilmente conseguirei abordar de maneira ampla nos limites deste artigo. Seguirei o seguinte percurso argumentativo: em primeiro lugar, apresentarei brevemente algumas discussões teóricas sobre a memória como fenômeno social, cotejando-a com o campo estruturado da história como área de conhecimento. Neste primeiro momento, sintetizarei o enquadramento de ambas ainda no século XIX, para, na sequência, apresentar a crise instaurada a partir das experiências históricas extremas do século XX, principalmente, o chamado "Holocausto/Shoah", evento propulsor desta crise. Em um segundo momento, analisarei como os enquadramentos (e desenquadramentos) de ambas categorias são mobilizados para compreender um objeto específico - os jogos entre memória e história no caso das ditaduras militares latino-americanas (particularmente, o regime militar brasileiro). Ao final, feito este percurso crítico entre enquadramentos teóricos, revisões epistemológicas e analises aplicadas, voltarei à teoria para propor novas equações e categorias acerca da relação entre história e memória.

Parto da premissa de que a experiência histórica da "Era dos Extremos", aliada a reconfigurações especificas das sociedades contemporâneas, exigiu a revisão da equação teórica acerca das relações entre história e memória, tal como haviam sido estruturadas ao longo do século XIX e inícios do século XX. A emergência do testemunho e da memória subjetiva e intersubjetiva como chaves para a compreensão histórica, a partir de então, exigiram novos moldes teóricos, confirmando a memória como um dos campos de reflexão para o historiador, sobretudo para aquele que se dedica ao estudo do Tempo Presente (mas não apenas).

Michael Pollack ressalta que o enquadramento social das memórias não pode ser tomado como um dado a priori, a partir do qual se descrevem os conteúdos e funções da lembrança coletiva do passado:

(...) não se trata mais de lidar com os fatos sociais como coisas, mas de analisar como os fatos sociais se tornam coisas, como e por quem eles são solidificados e dotados de duração e estabilidade. Aplicada à memória coletiva, essa abordagem irá se interessar portanto pelos processos $e$ atores que intervêm no trabalho de constituição $e$ de formalização das memórias. ${ }^{3}$

Assim, o olhar do historiador deve entender a memória como objeto que é fruto do próprio processo histórico, perturbando, no limite, a própria compreensão objetiva do passado. Esta corda bamba epistemológica acaba por exigir do campo historiográfico uma revisão radical sobre os

\footnotetext{
${ }^{1}$ Professor Titular do Departamento de História da Universidade de São Paulo, Doutor em História Social e pesquisador do CNPq (Bolsa-Produtividade). Autor dos livros Coração Civil: a vida cultural brasileira sob o regime militar. São Paulo: Intermeios, 2017; e 1964: História do Regime Militar Brasileiro. São Paulo: Contexto, 2014. Agradeço ao CNPq o apoio financeiro ao projeto que redundou neste artigo.

${ }^{2}$ WALDMAN, Gilda. La historia en primera persona: mirada(s) al passado. Política y Cultura, n.41, 2014, p. 91-109. Universidad Autónoma Metropolitana Unidad Xochimilco. Distrito Federal, México.

${ }^{3}$ POLLACK, Michel. Memória, silêncio, esquecimento. Estudos Históricos, n.2, v.3, CPDOC/FGV, 1989, p. 4. SÆCULUM - REVISTA DE HistóRIA [39]; João Pessoa, jul./dez. 2018. 
enquadramentos clássicos da história e da memória, herdados do século XIX como objetos estruturados do conhecimento disciplinar. Como andar nesta corda bamba e, ao mesmo tempo, não abrir mão da objetividade do conhecimento sobre o passado? A única saída para o historiador seria aderir à guinada subjetiva e à deriva da história como ciência da linguagem?

Neste processo, também pleno de novas implicações políticas, instaurou-se uma aporia sobre a relação de contiguidade, que sempre fora tensa, entre conhecimento, narrativa e referente, sendo este último entendido como a experiência vivida no passado que servia como lastro essencial da história $e$ da memória. Não quero reiterar o princípio de a impossibilidade constitutiva da história e da memória remeterem ao vivido, à história acontecida, como se a crise de ambas só pudesse ser equacionada no desfiar das tramas do discurso e no fiar da ficção imaginativa. Aqui, remeto às ponderações feitas por Carlo Ginzburg (2002) às posições de Hayden White (1992) ${ }^{4}$, não escondendo minha preferência pelo primeiro. Para Ginzburg, mesmo reconhecendo que a escrita não tem uma relação direta $e$ transparente com a realidade referente, a conexão entre "provas" $e$ "verdade" no campo historiográfico não pode ser descartada de antemão. Isso não pressupõe, obviamente, fazermos a defesa do retorno ao fato e à crença na objetividade cega que orientaram os historiadores do século XIX.

\section{Rupturas da memória nacional: da memória do herói à memória da vítima}

Apesar da história e da memória, vistas como categorias de conhecimento e processos sociais, terem sofrido um conjunto de enquadramentos e delimitações acadêmicas a partir do século XIX, as suas interações são constituintes do campo de estudos sobre o passado que então se consagrou. Em grande parte, a história-disciplina gestada na tradição metódica e positivista nasceu "contra a memória", enquadrando uma série de operações metodológicas e críticas que colocavam sob suspeita o passado lembrado e narrado pela tradição oral e pela crônica. Um pouco depois da formatação inicial da história-disciplina, a memória também foi enquadrada como instituição social pela sociologia nascente. O conceito central de Maurice Halbwachs, "memória coletiva", consagrou este enquadramento sociológico dos processos de lembrança. ${ }^{5}$ Nele, a memória foi entendida como produto social que se situa nas intersecções entre o indivíduo e o coletivo, constituinte dos laços de coesão e estabilidade em uma dada sociedade. Não por acaso, como defende Michael Pollack, a versão mais acabada de memória coletiva, seria a memória nacional. ${ }^{6}$

Em que pese o fato de a historiografia tradicional do século XIX se arvorar em ser o exame crítico da memória, ao se dedicar prioritariamente aos estudos sobre o Estado-nação, os historiadores acadêmicos acabaram por reconstruir, ou mesmo chancelar, novos processos de memória. A historiografia nascente acabou se voltando para a consagração das soberanias nacionais e da ideia de civilização, tal como gestadas na Europa do oitocentos. O "túmulo do soldado desconhecido", uma das tradições inventadas mais poderosas pela era dos nacionalismos, representou a conciliação, a seu modo bem-sucedida, entre história e memória, entre o povo anônimo e as elites nacionais, entre a sociedade e o Estado-nação. ${ }^{7}$

Ocorre, entretanto, que as mudanças de foco sobre o passado em ambos os domínios - história e sociologia - passaram a questionar as delimitações e dicotomias herdadas do debate clássico. Não seria exagerado dizer que, nas últimas décadas do século XX, a memória invadiu o campo da história, ao mesmo tempo em que se tornou seu objeto de estudo. Passou a vigorar, portanto, uma nova relação entre história e memória, afirmada pelos acontecimentos extremos do século XX e pelo debate teórico que se seguiu. Surgiram novos desafios ao historiador, sobretudo àquele que se dedica ao estudo do chamado Tempo Presente. Nas palavras de Rodrigo Patto:

\footnotetext{
${ }^{4}$ GINZBURG, C. Carlo. Relações de força: história, retórica, prova. São Paulo: Companhia das Letras, 2002; WHITE, Hayden. Meta-história: a imaginação histórica no século XIX. São Paulo, Companhia das Letras, 1992.

5 HALBWACHS, Maurice. Les cadres sociaux de la memoire. Paris, Felix Alcan, 1935. Disponível em http://gallica.bnf.fr/ark:/12148/bpt6k11657053. Acessado em 08/01/2018.

${ }^{6}$ POLLACK, Michael. Memória, silêncio, esquecimento...

${ }^{7}$ HOBSBAWM, Eric; RANGER, Terence. A invenção das tradições. Rio de Janeiro, Paz e Terra, 1997. 
Não raro (...), o historiador é interpelado por pessoas que se sentem mais capazes para falar do passado recente, considerando seu testemunho superior ao olhar de um pesquisador que "não estava lá". Se as fronteiras entre História e Memória são esgarças e tênues, as dificuldades no presente caso são ainda maiores. ${ }^{8}$

A raiz desta clivagem está nos efeitos da guerra moderna e suas violências genocidas extremas, patentes a partir da Primeira e, sobretudo, da Segunda Guerra Mundial. Essas violências em massa, ao extrapolarem os códigos do campo de batalha, atingindo populações civis inteiras, abalaram as relações e interações tradicionais entre a história e a memória no campo teórico, acadêmico e político. Surgiu uma nova demanda sintetizada no "direito à memória" da vítima e do derrotado, algo bastante inédito até então. Via de regra, essa demanda ia de encontro ao ufanismo e às narrativas oficiais dos vencedores ou ao silêncio e ocultamento dos vencidos e das populações exterminadas, naturalizados pelas sociedades e civilizações triunfantes, em nome da defesa da nação, da civilização ou do progresso. Os estrategistas da guerra moderna, como nos lembra Domenico Losurdo ${ }^{9}$, sempre apostaram no esquecimento histórico dos crimes em massa e no descrédito social dos eventuais sobreviventes. Hitler teria dito, para minimizar o impacto futuro da "solução final" que levaria ao Holocausto judeu: "quem se lembra, hoje [1942], do extermínio dos armênios?". Entretanto, a memória apaziguada das violências extremas tornou-se impossível na nova conjuntura que se seguiu ao fim da Segunda Guerra Mundial.

Para muitos autores, se havia a possibilidade de uma "história após Auschwitz", ela residia precisamente em uma nova relação entre história e memória, radicalmente revista em termos epistemológicos e políticos. Uma profusão de "discursos sobre a memória" acabou por transformar a memória em objeto da história e em contraponto crítico que matiza as ilusões de objetividade da historiografia. Andreas HUYSSEN afirma que os discursos da memória aparecem em um contexto preciso, "como consecuencia de la descolonización y de los nuevos movimientos sociales que buscaban historiografías alternativas y revisionistas". ${ }^{10}$ Trata-se de um processo longo, com marchas $e$ contramarchas, mas que tem conhecido um movimento afirmativo desde o fim da Segunda Guerra Mundial, com a crescente importância dos "direitos humanos" como agenda geopolítica que, malgrado suas manipulações pelas potências hegemônicas, consagrou o tema dos "crimes contra a humanidade" em nível internacional. Esta nova configuração alimentou ( $e$ foi alimentada) pela crítica social às fontes tradicionais de autoridade, afirmando os direitos das minorias e o direito às suas memórias grupais. $\mathrm{O}$ debate internacional sobre os significados políticos e epistemológicos do Holocausto/Shoah adensaram este processo de revisão teórica.

A "invasão da memória" no campo da historiografia acabou por colocar em xeque o próprio conceito de representação do passado articulado ao seu referente, o fato vivido. As possibilidades de se representar, julgar e compreender as experiências-limite de violência em massa, foram amplamente problematizadas. As justificativas de natureza política, militar ou ideológica por parte dos vencedores ou das autoridades não mais apaziguaram o passado. A própria objetividade do campo historiográfico, suas operações metodológicas e seus métodos de exposição, passaram a ser vistos como insuficientes e incapazes de explicar este tipo de passado. ${ }^{11}$ Conforme Elizabeth Jelín,

En cualquier momento y lugar, es imposible encontrar una memoria, una visión y una interpretación únicas del pasado, compartidas por toda una sociedad. Pueden encontrarse momentos o períodos históricos en los que el consenso es mayor, en los que un 'libreto único' del pasado es más aceptado o aún hegemónico. Normalmente, ese libreto es lo que cuentan los vencedores de conflictos y batallas históricas. ${ }^{12}$

Do ponto de vista metodológico, a maior novidade surgida neste processo de revisão radical das bases tradicionais da história e da memória foi o recurso ao testemunho e a afirmação da "história

\footnotetext{
${ }^{8}$ PATTO SÁ MOTTA, Rodrigo. História, Memória e as disputas pela representação do passado recente. História. São Paulo, Unesp, v.9, n.1, p. 56-70, janeiro-junho, 2013.

${ }^{9}$ LOSURDO, Domenico. Guerra e Revolução: O mundo, um século depois de outubro de 1917. São Paulo: Boitempo, 2017.

${ }^{10}$ HUYSSEN, Andreas. En busca del futuro perdido. Cultura y memoria en tiempos de globalización FCE, México, 2002.

${ }^{11}$ RICOEUR, Paul, A memória, a história, o esquecimento. Campinas: Unicamp, 2007.

12 JELÍN, Elizabeth. Los trabajos de la memoria. Madrid: Siglo XXI, 2002, p. 34.
} 
oral" como veículo para a compreensão do passado. Ao privilegiar a análise dos excluídos, dos marginalizados e das minorias, a história oral ressalta a importância de memórias subterrâneas que, como parte integrante das culturas minoritárias e dominadas, se opõem à "memória oficial" das sociedades nacionais, ao acentuarem seu caráter uniformizador e opressor. ${ }^{13} \mathrm{~A}$ própria ideia de uma memória social orgânica e funcional, à la Halbwachs, foi colocada em xeque, dando lugar a "memórias implantadas", forjadas como artefatos culturais ad hoc aos grupos sociais para os quais se destinam, consumidas como parte da cultura de massa. A incorporação da memória como "bem cultural" consumível por parte de populações diversas e sem experiência comunitária ou simbólica comum de partilha, é definida por Allison Landsberg como "memória-prótese", produto de relações de poder multidirecionais diversas. ${ }^{14}$

Assim, penso que o debate que emergiu da reconfiguração histórica provocada pelo Holocausto, pela descolonização, pelo caráter multiétnico de sociedades centrais no mundo contemporâneo e pelas demandas de uma memória da vítima, instaurou uma dupla crise: na história, e na memória. Não se trata apenas de apontar os limites do método histórico em sua busca pela verdade, aliás já anunciada desde a hermenêutica do século XIX. Parece-me igualmente patente a crise no conceito de memória como instituição social na linhagem halbwachsiana, como caminho para a coesão social e como monumento que celebra algo coletivamente vivido, reforçando uma determinada identidade grupal dominante.

Afirmaram-se, como epicentro do debate, as questões vinculadas aos limites impostos à representação histórica, tanto no que diz respeito à exposição dos acontecimentos extremos pela linguagem científica e objetiva, como em relação ao alcance "realista" desta representação. A história tradicional foi desafiada em sua base epistemológica, qual seja, a de colar sua narrativa científica ao referente passado, ao "realmente acontecido", ainda que por mera aproximação verossímil. O "excesso de memória" revelava a "incompletude da história", entendida como conhecimento distanciado e objetivo, face à catástrofe moderna.

A constatação desta "dupla crise", hipótese central deste artigo, nos leva ao exame das consequências do revisionismo acerca dos limites da história como conhecimento e do consequente "excesso de memória" para superá-la. Dentre essas consequências estão os novos enquadramentos teóricos que celebram uma memória elaborada justamente a partir das lacunas traumáticas. Este tipo de equacionamento do impasse se baseia na valorização da memória subjetiva e do relativismo epistemológico, em defesa dos recursos à retórica imaginativa. Este seria o mapa para contornar não apenas a perda do que foi vivido na realidade - o referente -, mas pensar criticamente a experiência do "inassimilável, irrepresentável e incompreensível" das violências extremas.

Entretanto, bastaria afirmar os pressupostos do "desconstrucionismo" historiográfico para contornar essa crise de tão difícil equação? A constatação da saudável pluralidade de memórias sobre o passado, todas elas válidas enquanto discursos identitários e imperativos éticos, não resolve a equação do conhecimento histórico, ainda que ajude a problematizar o fetiche da objetividade factual do discurso tradicional da história. Por mais que se esgarce os limites da objetividade historiográfica, o compromisso com o real não pode ser abandonado de antemão. A busca do "real-acontecido", o referente do discurso e da operação historiográfica, é semelhante à cenoura do coelhinho de laboratório: está à nossa frente (seria melhor falar, neste caso, "às nossas costas"), tem materialidade, mas não podemos nunca alcançá-la, embora tenhamos o impulso de correr em sua direção.

\footnotetext{
${ }^{13}$ POLLACK, M. Memória, silêncio, esquecimento...

${ }^{14}$ LANDSBERG, Alison. Prosthetic Memory. The Transformation of American Remembrance in the Age of Mass Culture. Columbia Univ. Press, 2004.
} 


\section{Paradigmas de memória, valorização do testemunho e processos de superação da violência política}

Os processos de pacificação e transição que emergiram a partir de contextos históricos marcados pela violência política, tais como guerras, ocupações estrangeiras, genocídios e ditaduras, via de regra são acompanhados por complexas operações de reconstrução da memória e justiças de transição, conduzidas por atores e instituições das áreas de direito, psicanálise e história, coordenadas por elites políticas em contextos pós-conflito. O objetivo central seria o de superar as marcas traumáticas $e$ fissuras no tecido social e nas instituições, para a refundação de um mundo comum. Este movimento de "virar a página do passado" é marcado tanto por operações de esquecimento, quanto de lembrança, as quais envolvem uma ampla gama de atores sociais e políticos que disputam a hegemonia do processo.

As experiências e debates em torno do Holocausto/Shoah, os quais não poderemos esmiuçar por falta de tempo, serviram como paradigma central deste tipo de gestão da memória e de revisão do passado. Desde então, o regime de memória social mudou e o papel da vítima e do testemunho dos sobreviventes passou a ocupar um espaço relevante, tanto em relação ao nazismo, quanto às ditaduras latino-americanas, entre outros processos históricos. ${ }^{15}$

Este regime de memória, instituído nas últimas décadas para lidar com os processos coletivos traumáticos, tampouco está isento de dilemas e contradições políticas, com implicações no debate teórico aqui examinado. Por exemplo, há atores que não se sentem contemplados pelas "justiças de transição" e criam demandas específicas por "verdade" e "justiça" que podem ser ou não contempladas nesses processos de reconstrução, pacificação nacional ou redemocratização. Estas demandas reclamam o reconhecimento de fatos, a consideração de testemunhos, o estabelecimento de responsabilidades e punições aos perpetradores de violências extremas, seguido da formalização de expiações, reparações e perdões. Nos vários processos históricos dessa natureza, entretanto, a sequência ideal de ações - cristalizada na tríade "verdade, justiça, reparação" - nem sempre se mostrou viável, sendo sacrificada em nome da realpolitik e dos jogos de poder. Se o horizonte de uma memória consensual continua impossível, o objetivo final desse processo ainda é o apaziguamento e o perdão, visando a refundação das bases sociais na perspectiva democrática e pluralista.

Ao longo destes processos, os historiadores frequentemente são interpelados para confirmar os testemunhos das vítimas, e cooperam para o estabelecimento de responsabilidades e para a luta contra o esquecimento coletivo, reiterando o caráter pedagógico e moral do conhecimento histórico, sintetizado na expressão "nunca mais". Entretanto, não raramente, surgem conflitos entre a busca da verdade histórica, sempre plural e intersubjetiva, e a premência do testemunho, subjetivo e parcial, mais inclinada à veracidade do que à verdade. ${ }^{16}$ Via de regra, mesmo partilhando valores democráticos comuns, historiadores, militantes das causas humanitárias e testemunhas-protagonistas divergem sobre a explicação da natureza e sentido dos eventos matrizes ${ }^{17}$. Em outras palavras, história e memória podem lutar contra o esquecimento, contra o negacionismo e o trauma, mas nem sempre o fazem seguindo os mesmos procedimentos e partindo das mesmas premissas.

A questão do testemunho e seu estatuto teórico e metodológico para o historiador estão no centro desses novos regimes de memória e de história. Vale lembrar, que o testemunho não é o oposto das "operações historiográficas", conectando-se à "operação arquivística", primeira fase do ofício historiográfico. ${ }^{18}$ Enquanto "memória declarativa"19, o testemunho registrado é a base do arquivo, da fonte escrita, do documento tão cultuado pelos historiadores, mas nem por isso isento de crítica. ${ }^{20}$ No debate teórico contemporâneo, muitas vezes o testemunho, visto como expressão da subjetividade fraturada, tensiona o discurso historiográfico.

A matéria principal do testemunho é o acontecimento traumático, visto como desafio ao discurso histórico estruturado e objetivo. O trauma pode ser definido como uma experiência de choque que

\footnotetext{
${ }^{15}$ TRAVERSO, Enzo. El pasado, instrucciones de uso. Historia, memoria, política. Madrid: Marcial Pons, 2007.

${ }^{16}$ RICOEUR, Paul. A memória, a história, o esquecimento. Campinas, Unicamp, 2007.

${ }^{17}$ SARLO, Beatriz. Tempo passado. Cultura da memória e guinada subjetiva. Cia das Leras, 2007.

${ }^{18}$ DE CERTEAU, Michel. A Escrita da História. Rio de Janeiro: Forense-Universitária, 1982.

${ }^{19}$ RICOEUR, P. A memória, a história, o esquecimento...

${ }^{20} \mathrm{BLOCH}$, M. Apologia da história ou o ofício do historiador. Rio de Janeiro, Zahar, 2001.
} 
produz uma "imagem congelada de um passado que imobiliza a ação". ${ }^{21}$ Acrescentaríamos que ele não apenas imobiliza a ação, mas impede a lembrança (da vítima), desestruturando uma narrativa que dê, aos que não viveram a ação traumatizante, acesso a uma determinada verdade sobre o passado, a "verdade da vítima". Em situações-limite, a violência extrema gera traumas sociais que vão além das vítimas diretas, e os traumas geram esquecimento, processo que implica em revisão do passado que pode se desdobrar em silêncio completo sobre algo ("tabu") ou, mais comumente, em uma memória seletiva e lacunar. Não raro, a própria vítima individual desenvolve uma memória seletiva, e não encontra uma escuta social disposta a ouvi-la. O silêncio da vítima e a surdez dos outros (os cidadãos indiferentes, os coniventes com os crimes ou os algozes e seus herdeiros políticos e institucionais), foi muito comum logo após o fim da Segunda Guerra Mundial, quando os sobreviventes dos campos voltavam à vida civil. Só a partir dos anos 1960, com a "era do testemunho" inaugurada pelo julgamento de Adolf Eichmann em Jerusalém, este quadro começaria a mudar, com implicações teóricas amplas para o conhecimento histórico. ${ }^{22}$

O silêncio das vítimas e o esquecimento das violências são desafios não apenas à memória dos que viveram e sofreram, mas à construção do conhecimento histórico como um todo. Conforme Pollack, há dois tipos de silêncio: do perpetrador e da vítima. "Silêncio do perpetrador é diferente do silêncio da vítima. O silêncio do perpetrador encontra respaldo no discurso oficial do poder em vigência ou das suas redes de proteção institucionais após a queda política". ${ }^{23}$ Eu acrescentaria que nem todo silêncio é trauma. Se esta assertiva tiver alguma validade, os paradigmas de enquadramento da memória no caso das ditaduras latino-americanas e de outras sociedades nacionais pós-conflitivas devem ser revisados na direção de uma memória-tabu, que também interdita a revisão do passado e está na origem da nostalgia sobre o regime autoritário que vem ocupando o espaço público. ${ }^{24}$ Não é raro que o próprio testemunho da vítima tenha que enfrentar tabus, paralelamente ao enfrentamento dos traumas.

No enquadramento teórico de superação do trauma e elaboração crítica da experiência histórica que está na origem dos processos e justiças de transição, o silêncio da vítima precisa de uma escuta para ser rompido, e seu testemunho precisa encontrar condições sociais/políticas/culturais de reprodução e legitimação. Portanto, para a vítima, o silêncio não se dá apenas porque ela não se lembra, traumatizada diante do inacreditável, indizível e irrepresentável. Ele também ocorre quando não há uma escuta social possível, sobretudo quando seus perpetradores ainda ocupam cargos de destaque e influência na sociedade e no Estado, mesmo em processos de transição democrática. Entre a testemunha como iniciativa individual, vista como expressão da "coragem civil" diante do esquecimento imposto pelo coletivo, e o testemunho como instituição de acesso ao passado, legitimado pela historiografia, há um longo caminho, nem sempre direto e linear.

No momento inicial dos processos sociais de pacificação e refundação, é comum que a vítima apresente dificuldades para testemunhar, ainda que existam ouvintes. Aqui, a soma dos traumas individuais afirma-se como desafio ao conhecimento do passado coletivo. Isto é mais dramático em processos históricos onde faltam documentos escritos ou registros visuais. Os indícios da tortura e do genocídio são geralmente apagados pelos aparatos do poder perpetrador, e o desaparecimento forçado das vítimas mortas é seu corolário (como na ditadura argentina ou no extermínio de judeus sob o III Reich, por exemplo). É muito comum na história contemporânea, que os acontecimentos traumáticos sejam recordados apenas pela via da lembrança privada ou comunitária, podendo gerar uma "guetificação" da memória, cujo melhor exemplo talvez seja o caso do genocídio armênio de 1915. Entretanto, à medida em que o testemunho ganha estatuto de conhecimento legítimo do passado para a sociedade como um todo, estas memórias reprimidas da "vítima" ganham o espaço público, na forma de processos judiciais e processos historiográficos de amplo impacto, rompendo os limites do grupo de origem. Ao se tornarem narrativas públicas, extrapolam seu caráter inicialmente

\footnotetext{
${ }^{21}$ SELIGMAN-SILVA, Marcelo. Narrar o trauma - a questão dos testemunhos de catástrofes históricas. Psicologia Clínica, Rio de Janeiro, v.20, n.1, p. 65-82, 2008.

${ }^{22}$ Cf. WIEVIORKA, A. L' Ère du témoin. Paris: Plon, 1998; ARENDT, H. Eichman em Jerusalém. Um relato sobre a banalidade do mal. São Paulo: Companhia das Letras, 1999.

${ }^{23}$ POLLACK, M. Memória, silêncio, esquecimento...

${ }^{24}$ NAPOLITANO, Marcos. Recordar é vencer: as dinâmicas e vicissitudes da construção da memória sobre o regime militar brasileiro. Antíteses, Londrina, v.8, n.15 esp., p. 9-44, nov. 2015.
} 
funcional (jurídico ou historiográfico) e se afirmam como políticas de memória, bem como reivindicação de um direito à reparação material ou simbólica. Com o avançar deste processo, novos indícios materiais (edificações, objetos, paisagens) se somam ao testemunho, compensando as lacunas da documentação escrita, oficiosa ou oficial, sobre as violências. Esta vivência passa a ser objeto de "perlaboração" individual e coletiva - conceito psicanalítico que implica em um trabalho ativo visando superar o trauma e o recalque do evento que o gerou, evitando sua repetição compulsiva. ${ }^{25}$

A tradição crítica dominante nos estudos sobre o Holocausto e sobre as ditaduras latino-americanas defende que o testemunho traz em si a possibilidade de assimilação crítica daquele passado de violência extrema, pacificando as sociedades a partir da imposição da "verdade" e da "justiça". No limite, trata-se de uma utopia de refundação política, cultural e social. A psicanálise viria em socorro da história, supostamente impotente diante da fragilidade dos métodos objetivistas que estão no DNA da história-disciplina. Nesta perspectiva, a emergência da era do testemunho ${ }^{26}$, impõe o olhar subjetivo da vítima como reconstrução dos elos sociais, a partir de um trabalho de luto e do movimento institucionalizado de "rememoração, repetição, perlaboração". Vale lembrar, estas categorias remetem ao ensaio clássico de Freud, que ao lado de outro texto famoso - Luto e Melancolia - tem regido as discussões teóricas sobre o "passado histórico traumático". ${ }^{27}$

\section{Dilemas e impasses de um novo regime de memória}

O movimento de perlaboração crítica do passado visando a superação do trauma, calcado nos encontros da psicanálise com a história, esbarra em várias dificuldades, embora já tenha sido testado como ferramenta historiográfica no estudo das paixões e ressentimentos ao longo do tempo. ${ }^{28} \mathrm{~A}$ primeira é a dificuldade de representação, estágio primeiro do conhecimento. No debate teórico mais extremado, particularmente forte nos campos da filosofia, dos estudos culturais e da crítica literária, a representação do trauma gerado pelo acontecimento "impensável" é, no limite, "impossível". Não por acaso, tem partido destas áreas a crítica mais forte à história como ponte objetiva e acurada para o conhecimento do passado.

Nesta perspectiva, o testemunho poderia apenas em parte contornar esta "impossibilidade" $e$ "irrepresentatividade", na medida em que ele se assume como fragmentado, subjetivo e incompleto. O referente não apenas se perdeu no tempo, mas ele é irrepresentável no presente, posto que é trauma que cinde não apenas o "eu-vítima", mas o "nós-sociedade". A bela formulação literária de Primo Levi, que renunciou em falar "a verdade" sobre os campos de concentração, pois "a verdade estava com os mortos", parece estar na origem desta aporia. Se a verdade (histórica, poderíamos argumentar) está com os mortos, os exterminados, as vítimas mudas, todo testemunho é apenas aproximativo, apontando para um trauma, no limite, insuperável e constituinte da própria experiência contemporânea "pós-traumática", essencialmente lacunar. Por mais bem-intencionada e organizada, nenhuma "justiça de transição" poderia dar conta de tecer novamente a urdidura de uma sociedade traumatizada. Os próprios fios se dissolveram.

Além do impasse político que esta dificuldade acarreta, trata-se de uma equação difícil também sob o ponto de vista teórico, pois história e psicanalise não têm a mesma concepção epistemológica de tempo. Como aponta Régine Robin, recuperando as formulações de De Certeau,

Para a psicanalise, o esquecimento é ativo. Ele se insinua, ele retorna, pode até governar o presente. Para a historiografia, e essa será sua própria dificuldade em tratar os problemas da memória, existe um corte entre passado e o presente. Sem esse corte, nem a história, nem o saber, nem a operação cognitiva seriam possíveis. A história associa, quando a psicanalise desassocia. ${ }^{29}$

\footnotetext{
${ }^{25}$ FREUD, Sigmund. Recordar, repetir e elaborar: novas recomendações sobre a técnica da psicanálise II. In: Edição Standard Brasileira das Obras Psicológicas Completas de Sigmund Freud [ESB]. Rio de Janeiro: Imago, s/d., vol. XII, 1996, p.163-171.

${ }^{26}$ WIEVIORKA, A. L'ère du temoin...

${ }^{27}$ FREUD, Sigmund. Luto e Melancolia. São Paulo: Cosac-Naify, 2013.

${ }^{28}$ ANSART, Pierre. História e memória dos ressentimentos. In: BRESCIANI, Stella; NAXARA, Márcia (org.). Memória e (res)sentimento: indagações sobre uma questão sensível. 2 ed. Campinas: Unicamp, 2004, p. 15-36.; ANSART, Pierre. La gestion des passions politiques. L'Age de l'Homme. Paris, 1983.

${ }^{29}$ ROBIN, Régine. A memória saturada. Campinas: Ed. Unicamp, 2017.
} 
Nesta linha de argumentação, enfatiza-se uma impossibilidade epistemológica e ética da historiografia em lidar com o trauma. O culto à memória da vítima como acesso à experiência histórica extrema de um passado violento parece não resolver esta crise. Neste caso, o viés do testemunho, da escuta social e do luto completado pela perlaboração é confrontado o tempo todo com o impensável, o irrepresentável, o inenarrável, em um movimento que pode se aproximar de uma espécie de miseen-abyme teórico, deriva da hipernarrativa sem fim que afasta o referente passado do conhecimento possível e objetivo no presente. ${ }^{30}$ Mas, neste ponto, um novo problema se coloca: a afirmação do "irrepresentável", como resguardo ético da memória da vítima, sobre a qual todo discurso historiográfico seria incompleto, pode levar ao esquecimento?

Este enquadramento acirraria, portanto, a dupla crise anteriormente exposta - da história e da memória, seus lugares e funções sociais. Suas consequências não são apenas epistemológicas, mas também políticas e sociais, posto que a dimensão gnoseológica da história - o conhecimento prático propiciado pela reflexão crítica sobre o passado - fica comprometida.

Além dos enquadramentos de memória advindos do debate sobre o Holocausto/Shoah, há um outro paradigma de estruturação de memórias pós-conflito, com especial impacto nas narrativas sobre as ditaduras latino-americanas: a memória da "resistência", tal como foi configurada na experiência das "resistências antifascistas" construídas a partir de imperativo ético e humanista, mais do que ideológico. Isto ocorreu porque o nazi-fascismo foi visto, justamente, como ápice da opressão de um grupo político que encarnaria o "mal absoluto" sobre a sociedade "como um todo", dada a intensidade e abrangência da ação repressiva organizada pelo aparato estatal. As implicações $e$ contradições políticas e historiográficas desta memória da resistência tem sido estudada por vários autores em perspectiva crítica, a partir dos anos $1970 .{ }^{31}$

Como aponta Denise Rollemberg, a questão da "resistência" exige uma reflexão conceitual $e$ teórica, situando-se na interação entre a demanda por memórias de grupos políticos hegemônicos em processos de transição política pós-conflito e a produção historiográfica, no fim da Segunda Guerra Mundial. A principal demanda foi por uma nova memória oficial dos vários grupos que reconstruíram as nações invadidas e dominadas pelos nazifascistas e que se viam como herdeiros políticos da "resistência". As produções oficiais e revisionistas da historiografia francesa entre os anos 1960 e 1990 são um exemplo alentado de como o debate sobre a "resistência" (no caso, a França contra os invasores alemães) pode ser multidirecional, envolvendo polêmicas sobre identidades políticas $e$ étnicas, mitos nacionais, projetos políticos, e enfrentamento de tabus (como o colaboracionismo "espontâneo" em nome do anticomunismo e do antissemitismo comum entre franceses e ocupantes nazistas). Vale lembrar que tanto a Itália como a Alemanha têm um forte debate historiográfico sobre o tema da "resistência", ainda que menos influente na América Latina do que o debate francês. ${ }^{32}$

Nestes dois casos - "Resistências" e "Holocausto" - podemos falar em "regimes de memória" dominantes no mundo contemporâneo, com roteiros de afirmação institucional, valores éticos e categorias conceituais próprias. Estes dois paradigmas de memória ensejam uma crítica teórica que exige um realinhamento entre história e memória, ao mesmo tempo em que tensionam a relação entre a memória nacional e a memória de minorias, entre memória heroica das resistências e memória da vítima, redimensionando o papel do Estado em processos de reconstrução democrática e refundação social.

Pode haver várias memórias da Resistência contra opressões extremas de diversas naturezas (totalitarismos, colonialismos, extermínios, escravidão), assim como várias memórias do Holocausto/Shoah, mesmo a partir da perspectiva das vítimas. Mas estas memórias encontram seu denominador comum na afirmação de um imperativo ético, o de resistir à opressão quando esta encarna o "mal absoluto", cuja expressão simbólica máxima foram os massacres de civis durante a ocupação nazifascista e os campos de extermínio.

\footnotetext{
${ }^{30}$ SELIPRANDY, Fernando. Documentário e memória intergeracional das ditaduras do Cone Sul. Tese (Doutorado em História Social), Universidade de São Paulo, 2018.

${ }^{31}$ PAXTON, Robert . La France de Vichy 1940-1944. Paris, Éditions du Seuil, 1973; ROUSSO, Henry. Le syndrome de Vichy: de 1944 à nos jours. Éditions du Seuil, Paris, 1990; ROLLEMBERG, Denise. Resistência. Sarandi-PR: Alameda Editorial, 2016.

${ }^{32}$ ROLLEMBERG, Denise. Resistência... 


\section{Holocausto e Resistência como paradigmas de memória no estudo das ditaduras latinoamericanas}

Os diversos processos de transição política no Cone Sul latino-americano, nos quais não poderemos nos aprofundar nos limites deste texto, ensejaram relações peculiares entre história e memória. ${ }^{33}$ Há um debate abundante que dialoga com os paradigmas teóricos do testemunho, trauma, justiça de transição e discute os usos e abusos da memória e seus enquadramentos. ${ }^{34}$ Não raro, abundam nas narrativas historiográficas, sobretudo na Argentina, um vocabulário extraído da memória do Holocausto/Shoah, tais como testemunho, trauma, verdade, genocídio, a estratégia concentracionista da repressão, sem falar na teorização do "poder desaparecedor" do Estado repressor. ${ }^{35}$ Igualmente, as narrativas da resistência contra os regimes militares remetem às categorias e imagens construídas na luta contra o nazi-fascismo.

O caso brasileiro é bastante peculiar e ambíguo. Por um lado, houve uma transição moderada e inclusiva dos antigos quadros do regime militar, acompanhada de um compromisso político estabelecido por liberais e militares em não punir os responsáveis pelas violações aos direitos humanos. Por outro, consagrou-se uma memória hegemônica calcada na condenação simbólica do regime e suas violências (censura, tortura, desaparecimentos), no elogio à "resistência" genérica e na afirmação de uma "sociedade vítima", que coloca lado a lado liberais e esquerdistas. ${ }^{36}$ Nas lembranças sociais sobre o regime militar brasileiro há um conjunto de linhagens de memórias plurais $e$ desencontradas, em conflito: a) a memória das esquerdas (intelectuais, movimentos, sindicatos) que desde o fim dos anos 1970 tende a igualar as lutas por democracia e justiça social, embora não tenha consenso sobre o lugar da luta armada na história recente; b) a memória dos liberais, muito forte na imprensa, em algumas entidades civis e no sistema político, crítica dos desmandos do regime, mas igualmente crítica do "populismo" e da "luta armada"; c) a memória militar institucional, tratada pelas Forças Armadas como "tabu", como época a ser esquecida e silenciada; d) a memória da direita e extrema-direita, nostálgica da ditadura, que até pouco tempo não tinha lugar no espaço público, mas que sempre foi forte em círculos privados, familiares e redes sociais, e agora ocupa lugar até na mídia liberal e no sistema político-partidário.

Apesar desta cacofonia, crescente à medida que se agravou a crise da democracia brasileira depois de 2015, ainda vivenciamos a hegemonia de uma memória sobre o regime militar sobre as outras. Esta memória hegemônica é uma mistura da memória de esquerda (construída, sobretudo, por comunistas e nacionalistas de esquerda) e da memória liberal, construída ao longo dos anos 1970, por conta do afastamento político dos liberais em relação à fase mais repressiva do regime. Nela, operam os regimes de memória delineados neste texto, com peso maior para a categoria paradigmática da "resistência", embora a questão da "vítima", tal como emergiu no debate sobre o Holocausto, não esteja completamente ausente.

No caso brasileiro, portanto, ao contrário de uma história oficial, estamos diante de "memória

\footnotetext{
${ }^{33}$ Nosso foco nesta seção serão os casos brasileiro e argentino, como base para o debate teórico aqui proposto. Os casos paraguaio, chileno e uruguaio têm semelhanças e diferenças em relação aos casos brasileiro e argentino. Sobre estes outros casos ver ROCHA, Marina M. Lira. "El río nos quedó adentro": Direitos Humanos e os debates sobre desaparecimento forçado e genocídio na Justiça de Transição do território rio-platense. Tese (Doutorado em História Social), Universidade de São Paulo, São Paulo, 2018; RICO, Alvaro (org). Uruguay: cuentas pendientes. Dictadura, memorias y desmemorias. Ediciones Trilces, Montevideo, 1995; BURIAMO, Ana. Ley de Caducidad en Uruguay y esencia ético-política de la izquierda. Perfiles Latinoamericanos, 19/38, México, jul./dic. 2011, p. 173-203. Sobre o caso chileno ver WALDMAN, Gina. A cuarenta anos en torno del golpe militar en Chile: reflexiones en torno a comemoraciones y memorias. Revista Mexicana de Ciencias Políticas y Sociales. Universidad Nacional Autónoma de México Nueva Época, Año LIX, n. 221, mayo-agosto de 2014, p. 243-266.

${ }^{34}$ NAPOLITANO, Marcos. Recordar é vencer...; CAPELATO, Maria Helena. Memória da ditadura militar argentina: um desafio para a história. Clio. Revista de Pesquisa Histórica, 24, Recife, p. 61-81, 2006; WALDMAN, G. La historia en primera persona...; MARCHESI, Aldo et alli (org). No hay mañana sin ayer. Batallas por la memoria histórica en el Cono Sur. Buenos Aires, 2015; SARLO, Beatriz. Tempo passado...; JELÍN, Elizabeth. Los trabajos de la memoria...

${ }^{35}$ CALVEIRO, Pilar. Poder e desaparecimento: os campos de concentração na Argentina. Tradução Fernando Correa Prado. São Paulo: Boitempo, 2013.

${ }^{36}$ ROLLEMBERG, Denise. Esquecimento das memórias. In: MARTINS FILHO, João Roberto. O golpe de 1964 e o regime militar. Novas Perspectivas. São Carlos: Edufscar, 2006; REIS FILHO, Daniel Aarão. Esquerdas, ditadura e sociedade. Rio de Janeiro, Jorge Zahar, 2000.
} 
hegemônica", com implicações teóricas próprias para o campo da historiografia. ${ }^{37}$ Ela pode nascer contra a tentativa de um discurso oficial (entendido como ação consciente das elites políticas $e$ intelectuais que ocupam o Estado em determinada conjuntura) em impor seus valores, silêncios $e$ lacunas. Em conjunturas repressivas ou processos de violência política (do Estado), o discurso oficial tenta reconstruir o passado, mas muitas vezes não consegue estabelecer um consenso institucional $e$ social mínimo para impor uma forma de memória dominante que não seja um "consenso forçado" (contradição em termos) sob coerção, à base de vetos. Assim, surge a possibilidade de uma memória hegemônica às expensas do discurso oficial, sem prejuízo de interações completas entre ambos.

Esta memória hegemônica construída basicamente por atores não-estatais - imprensa, intelectuais, pesquisadores acadêmicos, artistas, grupos de direitos humanos e familiares, militantes de oposição só recebeu uma contraface tardia por parte do Estado brasileiro, como atestam as "Leis Memória" de 1995 e 2002 (sobre os desaparecidos e as reparações cabíveis, respectivamente), o III Plano Nacional dos Direitos Humanos (2007) a instauração da Comissão Nacional da Verdade (2012). Estas iniciativas não foram suficientes para reverter o quadro de impunidade imposto pela transição negociada e pela conciliação chancelada pelo sistema político, dada a blindagem política e jurídica dos torturadores. Ao que parece, apenas os familiares e grupos de Direitos Humanos, de presença importante, mas reduzida na sociedade brasileira (se compararmos com a situação argentina, por exemplo), reclamam por outra memória, na qual a punição aos perpetradores seria condição básica para a reconciliação democrática. ${ }^{38}$ No Brasil, dada a pluralidade de atores (mesmo com o recente avanço conservador na vida política e social) e a composição heterogênea da elite política e cultural pós-ditadura (composta por liberais moderados, quadros fisiológicos sem perfil ideológico claro e exmilitantes da oposição de esquerda que se inseriram no sistema partidário, mas com mais ampla penetração nos sistemas culturais), sem falar do alto nível de institucionalização do regime militar, não foi possível nem uma história oficial pós-transição, porque os atores do próprio campo oposicionista não convergiam em pontos essenciais. Tampouco houve condições para a afirmação de uma memória oficial, posto que o Estado e seus aparelhos não compartilharam um só discurso em relação ao regime, ao menos até o Relatório oficial da Comissão Nacional da Verdade (2014). Mesmo depois disso, continua a sensação de que as Forças Armadas, os Ministérios da Justiça (e o Sistema Jurídico), e a Secretaria de Direitos Humanos, por exemplo, continuam reféns da cacofonia oficial de memórias sobre a ditadura.

Isto significa que o Brasil é um "país sem memória", que não acertou suas contas com o passado? Este é um clichê muito comum no meio social leigo ou historiográfico, muito difundido sobretudo em relação à memória do regime militar. Entretanto, parece problemático afirmar que a sociedade brasileira se preocupa menos com a preservação da memória, ou seja, um "país sem memória".

No caso da ditadura brasileira há um debate público e acadêmico sobre o tema, há uma profusão de memoriais, políticas de arquivo, monumentos, filmes, obras memorialísticas e acadêmicas. O que ocorre, talvez, é que tanto a cultura da memória (entendida como a memória da história recente), como a memória histórica no conjunto da sociedade brasileira têm lugares e papeis mais plurais $e$ dispersos, se compararmos com os países da América do Sul, atuando de maneira polimorfa e desconexa como expressões coerentes de uma identidade social e política. Um exemplo concreto: não é incomum um mesmo cidadão ser "contra a ditadura", e defender que "direitos humanos só defendem bandidos", o que, no contexto atual, representa a mescla esquizofrênica de valores de esquerda e de direita. Nos limites deste texto, não poderei aprofundar uma reflexão a respeito destas incoerências e fragilidades, mas as fragilidades do sistema de ensino talvez estejam na sua base. Mas neste caso, trata-se de um mosaico de memórias desencontradas e disfuncionais, que convive com discursos mais estruturados e coerentes que circulam em círculos e grupos sociais mais restritos (como na universidade, na imprensa e nas artes).

Assim, temos vários níveis estruturados de memórias que se tensionam e interagem: a memória social mais difusa, a memória nacional institucionalizada, a memória oficial sobre determinados processos políticos e a memória hegemônica dominante nos sistemas culturais, artísticos e nos meios

\footnotetext{
${ }^{37}$ NAPOLITANO, Marcos. Recordar é vencer...

${ }^{38}$ TELES, Janaína. Os familiares de mortos e desparecidos e a luta por verdade e justiça no Brasil. In: TELES, Edson; SAFATLE, Vladimir (org.). O que resta da ditadura. São Paulo: Boitempo, 2010. 
de comunicação mais valorizados. Em todos estes espaços e redes de memória, a historiografia (ou alguns elementos dela) podem estar presentes. Assim, não se trata de opor, de maneira simplista, memória e história (historiografia), mas de entender padrões de interação e conflito entre uma e outra. O lugar secundário dos historiadores na $\mathrm{CNV}$, em que pese a densidade da historiografia brasileira sobre o golpe e o regime, é revelador desta tensão.

O que importa para nossa argumentação, é que esta memória hegemônica sobre a ditadura brasileira também se funda na ideia de uma "resistência democrática" ecumênica e da "sociedade vítima" da ditadura, e aqui defendo que operam as duas grandes estruturas narrativas de memória do século XX já citadas: a Resistência ao nazi-fascismo e Holocausto/Shoah (este em menor grau no caso brasileiro do que no argentino).

A memória da resistência atualiza o sentido do heroísmo e da ação heroica na História, pois reivindica sua luta em nome da humanidade e não apenas da nação ou de um parti pris. A memória do Holocausto/Shoah impõe a perspectiva da vítima no processo de compreensão do passado, a partir do seu testemunho. Ambos se tornaram imperativos ético-políticos que estruturam um regime de memória voltado para a reconstrução das sociedades atravessadas por processos de violência política, como no caso das ditaduras latino-americanas. A apropriação destes dois paradigmas, entretanto, não está isenta de riscos e contradições, posto que as experiências históricas que estão na origem dos golpes militares e das ditaduras que se seguiram, foram frutos de processos históricos peculiares a cada sociedade do "Cone Sul" (Brasil incluído), ainda que apresentem semelhanças e similitudes.

$\mathrm{Na}$ imbricação da memória da Resistência e da memória do Holocausto/Shoah, os resistentes são heróis e vítimas a um só tempo, tal como foi evidenciado no caloroso debate francês em torno do julgamento de Klaus Barbie nos anos 1980, chefe da Gestapo conhecido como o "açougueiro de Lyon". São heróis porque resistiram ao poder opressor, são vítimas porque este poder opressor é tão assimétrico e violento que os conceitos tradicionais de guerra não dão conta de compreender $e$ assimilar a violência do conflito. Esta leitura de uma dada experiência histórica ajudou a configurar a vítima-resistente e o resistente-vítima como herói por excelência da história do Tempo Presente. O resultado da incorporação das "vítimas-resistentes" no contexto sul-americano foi a clivagem entre narrativas valorativas e ideológicas das organizações armadas dos anos 1960, que defendiam a violência revolucionária, $e$ as narrativas humanitárias que condenavam a violência de Estado, predominantes nas transições democráticas latino-americanas. ${ }^{39}$ Não por acaso, a base destas novas narrativas foi o testemunho dos sobreviventes e a valorização da memória sobre os mortos $e$ desaparecidos pela repressão política.

Nas transições latino-americanas, tal como no paradigma do Holocausto/Shoah, o testemunho da vítima sobrevivente transformou-se em uma ponte para a verdade jurídica, mas foi questionado como caminho para a verdade histórica, conforme apontou Beatriz Sarlo em relação aos juicios dos militares argentinos acusados de violações de direitos humanos. ${ }^{40}$ Para a autora argentina, quando os conceitos de testemunho e de vítima dominam o processo, a subjetividade dá o tom dos debates, podendo enviesar as análises sobre o passado, dirimir experiências e interditar a crítica. Neste caso, as partes em luta são vistas unicamente como vítimas ou perpetradores, obscurecendo os projetos políticos que estão na origem do conflito $e$ as adesões sociais de diversos graus aos regimes autoritários. Esta visão vem sendo criticada por vários autores, que procuram explicar o processo de deterioração do convívio político e da violência social que marcou o terrorismo de Estado argentino, identificando sua gênese no período anterior à ditadura. ${ }^{41}$ Para estes autores, esse processo de violência teve na militância revolucionária de esquerda um polo ativo que, portanto, não pode ser visto como mera vítima passiva da história.

No limite, este regime de memória calcado na ideia de vítima-resistente, poderia reforçar a visão de uma sociedade inocente que se tornou vítima coletiva do Estado ditatorial, ou, conforme a versão

\footnotetext{
${ }^{39}$ MARKARIAN, Vania. Left in Transformation: Uruguayan Exiles and the Latin American Human Rights Network, 19671984 . London: Routledge, 2013.

${ }^{40}$ SARLO, Beatriz. Tempo passado...

${ }^{41}$ VEZZETI, Hugo. Sobre la violência revolucionaria. Memorias y Olvidos. Buenos Aires: Siglo XXI, 2009; FRANCO, Marina. Un enemigo para la nación. Orden interno, violencia y "subversión”, 1973/1976. Buenos Aires: Fondo de Cultura Económica, 2012.
} 
liberal, vítima dos "dois demônios", da repressão (sem limites) da direita e dos grupos armados de esquerda? Neste caso, ao invés de perlaboração crítica do passado, configura-se um álibi histórico que tem duas implicações básicas. Por um lado, obscurece os apoios, adesões e cumplicidades entre grandes segmentos sociais (sobretudo das elites e classes médias) e os perpetradores de violência massiva e sem limites que se materializou no sistema de repressão. Por outro, iguala, ética $e$ politicamente, o "direito à rebelião" contra um poder tirânico (um princípio fundante das sociedades democráticas modernas) a um sistema de repressão sem limites humanitários, que tem como base a tortura generalizada e o desaparecimento do "inimigo absoluto", o "subversivo".

Reitero a pergunta: neste caso, estamos diante de traumas ou tabus?

O resultado é uma visão dicotômica que vê o processo histórico dos regimes militares como o encontro, desigual e fortuito, entre vítimas e perpetradores como sujeitos centrais do processo histórico. Nesse ponto, a análise histórica deve se curvar ao imperativo ético (e político), potencializando o conflito entre história e memória. Manuel Garretón sintetizou de maneira brilhante este dilema historiográfico, ao proferir um verdadeiro axioma sobre os desaparecidos políticos das ditaduras: "não se pode saber o que eles fizeram, antes de sabermos o que foi feito deles".

Entretanto, "para saber o que foi feito deles" também é preciso um reexame crítico dos marcos teóricos à la mode, tanto centrados no trauma inenarrável e na irrepresentabilidade do acontecido, como na visão heroica e homogeneizante da "resistência". O risco de um enquadramento à fórceps da memória recente destes contextos em paradigmas teóricos dominantes pode resultar no efeito contrário do que almejam: o culto nostálgico às ditaduras, processo particularmente grave no caso brasileiro.

\section{Uma história da memória: um novo campo de reflexão para superar as aporias?}

Aqui, o debate teórico encontra-se em um dilema que não é apenas epistemológico e teórico, mas também ético e político: se é consensual que a historiografia tradicional, seus enquadramentos e sua crença em uma narrativa objetiva e verdadeira não conseguem dar conta do "acontecimento traumático", será que o recurso à memória elaborada e ao testemunho da vítima poderiam compensar estas lacunas e impossibilidades?

Régine Robin sintetizou este outro dilema, problematizando o "excesso de memória" que interdita toda reconciliação com o passado e toda distância crítica. Na perspectiva da autora o excesso de memória, como no conto de Borges (Fulnes, el memorioso), pode nos conduzir a uma nova forma de esquecimento:

Esse excesso de memória que nos invade hoje poderia ser apenas uma figura do esquecimento, pois a nova era do passado é a da saturação (...) saturação por inversão de signos, suspensão de um passado próximo mas não pensado, não criticado, não desencantado (...) Saturação por uma equiparação dos 'demônios' nazista e comunista, por uma indistinção dos acontecimentos, (...) saturação, enfim, por causa do fantasma de 'tudo guardar' que acompanham nossa imersão no mundo do virtual. ${ }^{42}$

Todas as reflexões apontam para um debate historiográfico que, desafiado pela historicização do passado recente e pela necessidade de recompor tecidos sociais traumatizados ou conspurcados por processos de violência, tem se afirmado nos últimos anos. ${ }^{43} \mathrm{O}$ debate vem tentando reconciliar as relações entre a história e a memória, frequentemente apelando para um novo campo de pesquisa, que poderíamos chamar de "história da memória". Todo arsenal teórico exposto anteriormente é mobilizado neste debate e na delimitação deste novo campo. O direito à memória das vítimas e a necessidade de uma memória crítica das resistências, para compreender os processos transicionais, entretanto, nem sempre convergem.

A memória das vítimas se materializou em monumentos e memoriais, cujo esforço é sempre lembrar, lembrar, lembrar. Como se lê nas placas nas escolas e praças de Paris, com a lista das crianças

\footnotetext{
${ }^{42}$ ROBIN. Memória saturada..., p. 22.

${ }^{43}$ PÉROTIN-DUMON, Anne. Verdad y memória. Escribir la historia de nuestro tiempo. In: PÉROTIN-DUMON, Anne (dir.). Historizar el pasado vivo en América Latina. Santiago de Chile: Universidad Alberto Hurtado, 2007; FRANCO, Marina y LEVÍN, Florencia. El pasado cercano en clave historiográfica. In: FRANCO, M. y LEVÍN, Florencia. Historia reciente. Perspectivas y desafíos para un campo en construcción, Buenos Aires, Paidós, 2007.
} 
deportadas e mortas em campos de concentração nazistas: "leia o nome destas crianças, ela é a única garantia contra o esquecimento". Se o já mencionado túmulo do soldado desconhecido, Clio submete Mnemosine, neste outro caso temos a mãe Mnemosine querendo educar a filha Clio.

No limite, na era das catástrofes e das vítimas, qualquer conciliação entre memória e história parece ser impossível. A demanda de memória das vítimas não apenas exacerba a aporia entre ambas, mas explicita uma crise da memória e da história, tal como foram pensadas no século XIX. As revisões que ampliaram o campo no século XX - a revolução da Escola dos Annales, a disposição crítica do marxismo ou mesmo a guinada subjetiva e linguística - tampouco parecem dar conta destes novos desafios. O chamado "fim das utopias", seja a da humanidade, do progresso ou da revolução, parece ter instaurado uma crise de consciência e ação, qual seja, a impossibilidade de agir conscientemente para construir, e não apenas conhecer, a história.

De todo modo, a revisão historiográfica dos processos de memória nos coloca um desafio, como historiadores e cidadãos. Um desafio ético, epistemológico e metodológico: Como fazer da memória o objeto da história sem que o historiador, cidadão do seu tempo, a transforme em uma cobaia asséptica de laboratório? Como fazer da memória o objeto da história, sem que esta fique cativa daquela? ${ }^{44}$ Como conciliar o direito à memória pautada pela subjetividade, com o distanciamento necessário ao ofício do historiador, mesmo aquele engajado em afirmar o direito à verdade e à justiça contra a violência e o arbítrio?

O excesso de demandas por memórias parece interditar, ao mesmo tempo, toda reconciliação com o passado e toda distância crítica, as duas bases estruturantes da história como disciplina. Se há apenas "encontros perdidos com a história", a memória pode ser, justamente, a baliza destes desencontros ${ }^{45}$, cujo saldo são ressentimentos e traumas que, no limite, impedem o apaziguamento da memória e da história, como sugeriu Paul Ricoeur. ${ }^{46}$

Neste cenário, história e memória devem ser pensadas sob o signo de uma incompletude constitutiva do conhecimento, mas que não devem ser sinônimos de incompreensão, irrepresentação ou impossibilidade. Caberia ao historiador, então, buscar equações teóricas que, mais do que conduzir a respostas inequívocas sobre o passado, orientem a formulação de novas perguntas, sem abrir mão da crença basilar de que algo realmente aconteceu, ainda que este algo sempre escape in totum.

Longe de certezas e ilusões, talvez a história seja apenas remorso, como sugeriu nosso grande poeta.

\footnotetext{
${ }^{44}$ MENESES, Ulpiano. T. B. A história, cativa da memória? Para um mapeamento da memória no campo das Ciências Sociais. Revista do Instituto de Estudos Brasileiros. São Paulo: 34. p. 9-23, 1992.

${ }^{45}$ ROBIN, R. "Memória saturada"...

${ }^{46}$ RICOEUR, P. "A memória, a história, o esquecimento"... 


\section{RESUMO}

Este artigo analisa os impactos teóricos $e$ historiográficos a partir da relação estabelecida entre história e memória como categorias de conhecimento sobre o passado. Partimos do princípio de que as experiências extremas pósSegunda Guerra Mundial obrigaram a um desenquadramento destas duas categorias, tal como haviam sido formatadas no século XIX, instaurando uma crise em ambas $e$ demandando por uma nova equação na interpretação do passado, sobretudo o chamado "passado recente". Esta crise, de efeitos epistemológicos, teóricos e historiográficos tem um impacto direto no debate sobre a memória e a história das ditaduras do Cone Sul, ao impor novos regimes de memória e de história. Nestes, o debate sobre "Resistência" e "Holocausto", advindos da experiência da Segunda Guerra Mundial e da luta contra o nazifascismo, ocupam um lugar central na memorização e na análise dos processos históricos recentes.

Palavras-chave: História e Memória: aspectos teóricos; América Latina: regimes militares; Brasil: ditadura militar; Argentina: ditadura militar.

\section{ABSTRACT}

This article analyzes the theoretical and historiographic impacts from the relation established between history and memory as categories of knowledge about the past. We assume that the extreme experiences of postWorld War II forced a dislocation of these two categories, as they had been shaped in the nineteenth century, instituting a crisis in both and demanding a new equation in the interpretation of the past, especially the socalled "recent past". This crisis has epistemological, theoretical and historiographic effects, with direct impact on the debate on the memory and history of the dictatorships of the South American (Southern Cone), imposing new regimes of memory and history on this subject. The debate on "Resistance" and "Holocaust", as historiographic concepts constructed from the experience of World War II and the struggle against Nazi-fascism, has a central role in the analysis and memorization of the South American dictatorships.

Key-words: History and Memory: theoretical aspects; Latin America: military regimes; Brazil: military dictatorship; Argentina: military dictatorship.

Artigo recebido em 16 jul. 2018.

Aprovado em 22 ago. 2018. 